\title{
The terminal structures of linear plasmids from Rhodococcus opacus
}

\author{
Jutta Kalkus, Renate Menne, Michael Reh and Hans G. Schlegel \\ Author for correspondence: Hans G. Schlegel. Tel: +49 55139 2364, Fax: +49 55139 3793, \\ e-mail: hschleg1@gwdg.de
}

Institut für Mikrobiologie der Georg-AugustUniversităt

Grisebachstrasse 8, D-37077 Gottingen, Germany

\begin{abstract}
The telomers of several linear plasmids of Rhodococcus opacus (formerly Nocardia opaca) were studied. The plasmids pHG201, pHG204 and pHG205 carry proteins bound to their ends, as shown by gel retardation experiments. A sequence hybridizing with the terminal sequence of pHG207, a recombinant linear plasmid consisting of the left part of pHG204 and the right part of pHG205, which was analysed in a previous study by the authors, could be detected in all linear plasmids of the wild-type $R$. opacus strains MR11 and MR22. However, only pHG204 and pHG206 carry terminal inverted repeats (TIRs) like pHG207. Cloning and sequencing of the terminal fragment of pHG204 revealed a nearly perfect TIR of $1016 \mathrm{bp}$. In contrast, the termini of pHG201 and pHG205 share little homology. Sequence analysis of the two end fragments of pHG201 revealed a similarity of only $65 \%$ within the terminal 34/32 bp and a perfect TIR of only $3 \mathrm{bp}$. The results support the assumption that long TIRs are not absolutely necessary for replication and maintenance of linear plasmids.
\end{abstract}

Keywords: Rhodococcus opacus, linear plasmid, terminal inverted repeat (TIR), terminal protein (TP)

\section{INTRODUCTION}

The genus Rhodococcus has become a subject of interest in several aspects, including phytopathogenicity (Vantomme et al., 1982), the degradation of xenobiotics (Dabrock et al., 1992), and biological production of hydrogen (Schneider et al., 1984; Zaborosch et al., 1989; Grzeszik et al., 1997a, b). The features mentioned are characteristics associated with and encoded on linear plasmids (Crespi et al., 1992; Dabrock et al., 1994; Kalkus et al., 1990).

The wild-type strains of $R$. opacus MR11 and MR22 each harbour three linear plasmids (Kalkus et al., 1990). The type strain MR11 (Klatte et al., 1994; Rainey et al., $1995)$ contains the linear plasmids pHG201 $(270 \mathrm{kbp})$, pHG202 (400 kbp) and pHG203 (420 kbp), and strain MR22 contains pHG204 (190 kbp), pHG205 (280 kbp) and pHG206 $(500 \mathrm{kbp})$. In the autotrophic transconjugant MR2253 originating from strain MR22 another linear plasmid, pHG207 (225 kbp), was found. The plasmids pHG201, pHG205 and pHG207 were

Abbreviations: LMP, low-melting-point; TIR, terminal inverted repeat; $T P$, terminal protein.

The GenBank accession numbers for the nucleotide sequence data reported in this paper are AF001834, AF001835 and AF007825. shown to enable the bacteria to grow chemolithoautotrophically on gaseous hydrogen and carbon dioxide (Aut character), leading to the name Aut elements (Kalkus et al., 1990). The smallest Aut element, pHG207, has been studied in detail previously (Fig. 1; Kalkus et al., 1993). It was shown to be the product of a single crossover recombination event between the wild-type plasmids pHG204 and pHG205. The left part of pHG207 (more than $120 \mathrm{kbp}$ ) originates from pHG204 and the right part (more than $80 \mathrm{kbp}$ ) originates from pHG205. The terms left and right refer to the restriction maps of the linear plasmids (Kalkus et al., 1993). Plasmid pHG207 carries an imperfect terminal inverted repeat (TIR) of $583 / 560 \mathrm{bp}$ and has proteins bound to its ends (terminal proteins, TP); this is consistent with the model proposed for invertrons (Sakaguchi, 1990).

To obtain more information on the general structure of linear plasmids we have investigated some of the other linear plasmids in $R$. opacus cells. These co-existing plasmids can be differentiated by selective markers such as the Aut character mentioned above, thallium resistance (pHG204), and the frequency of transfer. They are not simply derivatives or multimers of a single parental plasmid (Kalkus et al., 1993). In this study we demonstrate that pHG201, pHG204 and pHG205 carry TPs. Hybridization and sequence analysis showed that 
these plasmids are of two different types: pHG204 carries long nearly perfect TIRs, whereas in the Aut elements pHG201 and pHG205 the terminal sequences show only a weak similarity to each other.

\section{METHODS}

Bacterial strains, phage and plasmids. Sources and references of strains of Rbodococcus opacus used in this work are listed in Table 1. Escherichia coli XL-1 Blue and plasmid pBluescript SKM13 + were purchased from Stratagene. For preparation of single-stranded DNA, E. coli MV1184 and bacteriophage M13KO7 were used (Vieira \& Messing, 1987). Strains of $R$. opacus were grown in FM-TYE medium at $30^{\circ} \mathrm{C}$ as described previously (Sensfuss et al., 1986). Strains of E. coli were routinely grown in LB medium at $37^{\circ} \mathrm{C}$. If required, the medium was supplemented with ampicillin $\left(100 \mu \mathrm{g} \mathrm{ml}^{-1}\right)$, IPTG $\left(50 \mu \mathrm{g} \mathrm{ml}^{-1}\right)$ and X-Gal $\left(40 \mu \mathrm{g} \mathrm{ml}^{-1}\right)$. Cloning of the terminal fragments produced the hybrid plasmids listed in Table 2.

Isolation of linear plasmid DNA. Cells of $R$. opacus were embedded in high concentration in LMP agarose and lysed according to McClelland et al. (1987), using lysozyme, $N$ lauroylsarcosine, SDS and proteinase $\mathrm{K}$ as described previously (Kalkus et al., 1990). Isolation of linear plasmid DNA was achieved by electroelution from the agarose plugs, followed by precipitation of the DNA with ethanol and microdialysis against water (Kalkus et al., 1993). DNA of pHG206 was isolated by cutting the relevant band out of LMP agarose gels after separation of total DNA of MR22 from highly concentrated DNA-agarose plugs by PFGE. Treatments of pHG206 with restriction endonucleases were carried out in situ in LMP agarose. For preparation of non-proteolyticallytreated plasmid DNA, proteinase $\mathrm{K}$ was omitted.

Electrophoresis. PFGE was performed with the Pulsaphor system (Pharmacia) using $1 \%(\mathrm{w} / \mathrm{v})$ agarose slab gels and $0.5 \times$ TBE buffer (45 mM Tris $/ 45 \mathrm{mM}$ borate $/ 1 \mathrm{mM}$ EDTA, $\mathrm{pH} \mathrm{8.5)}$. The buffer was cooled to $13{ }^{\circ} \mathrm{C}$ and gels were run at $6 \mathrm{~V} \mathrm{~cm}^{-1}$. As size standards, HindIII- or PstI-cut $\lambda$ DNA or concatemers of $\lambda$ DNA (Waterbury \& Lane, 1987) were used.

Cloning of the terminal fragments. Terminal fragments were identified by gel retardation experiments (see Results). For isolation, linear plasmid DNA was prepared using proteinase $\mathrm{K}$ as described above and was digested with Sall. After separation by electrophoresis, the fragments were extracted from the agarose gel using glass milk (Geneclean, Bio101). The purified end fragments were ligated with the SalI-produced end to the Sall position of the vector (pSKM13+) and with the opposite end to a blunt end produced by EcoRV. The DNA was transferred into $E$. coli by electroporation (Ausubel $e t$ al., 1987).

Hybridization experiments. DNA was transferred by the Southern blot procedure (Ausubel et al., 1987) to a positively charged nylon membrane (Biodyne B, Pall Filtrationstechnik) and fixed on the membrane by UV irradiation (Khandjian, 1987). If not indicated otherwise, DNA used for hybridization probes originated from the hybrid plasmids listed in Table 2. To eliminate vector DNA, insert DNA was digested with appropriate restriction endonucleases, separated by electrophoresis, and purified from agarose gel. Hybridization probes were labelled with biotin-16-dUTP (Boehringer Mannheim) using a random primer kit (Gibco-BRL) and applying conditions as recommended by the manufacturer. Probes were purified via an exclusion chromatographic column (Sepharose

Table 1. Strains of Rhodococcus opacus used in this work

\begin{tabular}{|c|c|c|c|}
\hline \multirow[t]{2}{*}{ Strain } & \multicolumn{2}{|r|}{ Plasmids } & \multirow[t]{2}{*}{ Source or reference } \\
\hline & Circular & Linear & \\
\hline MR11 & pHG31-a, pHG31-b & pHG201, pHG202, pHG203 & $\begin{array}{l}\text { DSM 43205 }(=\text { DSM 427); } \\
\text { Aggag \& Schlegel (1973) }\end{array}$ \\
\hline MR22 & pHG33 & pHG204, pHG205, pHG206 & $\begin{array}{l}\text { DSM 3346; Sensfuss et al. } \\
\text { (1986) }\end{array}$ \\
\hline MR2246 & & pHG201 & Sensfuss et al. (1986) \\
\hline MR2249 & & pHG204 & Kalkus et al. (1993) \\
\hline MR2253 & & pHG207 & Kalkus et al. (1990) \\
\hline MR281 & pHG33 & pHG205 & Kalkus et al. (1993) \\
\hline
\end{tabular}

Table 2. Hybrid plasmids: vector pBluescript SKM13 + with insert

\begin{tabular}{|c|c|c|c|}
\hline Name & Insert & Description ${ }^{*}$ & Reference \\
\hline pHG207-L $\mathrm{L}_{K p n \mathrm{I}}$ & $2 \cdot 2 \mathrm{kbp} K p n \mathrm{I}$ fragment & Left end of pHG207 & Kalkus et al. (1993) \\
\hline pHG207-R & $2 \cdot 3 \mathrm{kbp}$ SalI fragment & Right end of pHG207 & Kalkus et al. (1993) \\
\hline pHG204-R & $3.0 \mathrm{kbp}$ Sall fragment & Right end of pHG204 & This work \\
\hline pHG201-L & $1.15 \mathrm{kbp}$ Sall fragment & Left end of pHG201 & This work \\
\hline pHG201-R & $2 \cdot 3 \mathrm{kbp}$ SalI fragment & Right end of pHG201 & This work \\
\hline
\end{tabular}

* The terms 'left' and 'right' refer to the macrorestriction maps of the linear plasmids (Fig. 1, Kalkus et al., 1990, 1993). 
G-50; coarse). Hybridization and detection of biotinylated probes were carried out as described by Oelmüller et al. (1990). Oligonucleotides were radiolabelled at the $5^{\prime}$ end with $\left[\gamma^{33} \mathrm{P}\right] \mathrm{ATP}$ using T4 polynucleotide kinase (Ausubel et al., 1987).

DNA sequence analysis. Sequence determination was carried out by the dideoxynucleotide chain-termination method (Sanger et al., 1977) with single-stranded or alkali-denatured double-stranded plasmid DNA. Radioactive sequencing was performed using a Sequenase version 2.0 sequencing kit (USB) and $\left[{ }^{35} \mathrm{~S}\right] \mathrm{dATP} \alpha \mathrm{S}$. Elimination of compressions was achieved by using $7^{\prime}$-deaza-dGTP or dITP. Oligonucleotides used as primers were synthesized in a Gene Assembler Plus apparatus according to the protocol provided by the manufacturer (Pharmacia LKB). For direct sequencing of pHG207, $10 \mu \mathrm{g}$ of proteolytically treated plasmid DNA was alkali-denatured in a standard procedure by adding $\mathrm{NaOH}$ to obtain a final concentration of $0.2 \mathrm{M}$. The solution was incubated for $5 \mathrm{~min}$ at $70^{\circ} \mathrm{C}$. The DNA was precipitated with ammonium acetate and ethanol at $-20^{\circ} \mathrm{C}$. After washing with $70 \%$ ethanol the denatured DNA was dissolved in water and was immediately used for the annealing procedure with $1 \mathrm{pmol}$ oligonucleotide primer (ATCGACGGCAACGGGAAT). The sequence reactions were done using $7^{\prime}$-deaza-dGTP. Sequence data were analysed using the software package GCG version 8 (Genetics Computer Group).

\section{RESULTS}

\section{Detection of regions hybridizing with the terminal sequence of pHG207 in other linear plasmids}

Because the linear plasmid pHG207 was shown to carry TIRs and to be a recombination product of the wildtype plasmids pHG204 and pHG205 of strain MR22, we assumed that TIRs are a general feature of the linear plasmids of $R$. opacus (Fig. 1). Furthermore, at least pHG204 and pHG205 should carry sequences homologous to the terminal sequences of pHG207. To examine the possible ubiquity of the terminal sequences of pHG207, the linear plasmids of $R$. opacus MR11 and MR22 were separated by PFGE, transferred to a nylon membrane and hybridized with a biotinylated DNA fragment representing the terminal sequence of the right end of pHG207 (0.6 kbp EcoRI fragment) (Fig. 2a, b). The experiment was repeated with less DNA to enable the distinction between pHG202 and pHG203 (data not shown). All linear plasmids from both wild-type strains gave significant signals with this probe.

To investigate this result in more detail, SalI digests of the linear plasmids pHG201, pHG204, pHG205 and pHG206 were hybridized with the same probe (Fig. 3). SalI digests of the control plasmid pHG207 showed two hybridizing fragments, corresponding to the right $(2.3 \mathrm{kbp}$ - originating from pHG205) and left $(4.0 \mathrm{kbp}-$ originating from pHG204) ends, as expected. Corresponding SalI digests of linear plasmids pHG204 and pHG206 also showed two hybridizing fragments each (Fig. 3), indicating the existence of two regions having homology with terminal sequences of pHG207, and suggesting that TIRs are a general feature of these linear plasmids.

In contrast, patterns of hybridization between the
pHG207 terminal sequence probe and restriction digests of pHG201 and pHG205 showed only one homologous Sall fragment $(2 \cdot 3 \mathrm{kbp})$ in each (Fig. 3a). The same result - only a single detectable fragment - was obtained in experiments in which the same probe was hybridized against $\mathrm{KpnI}(7 \mathrm{kbp})$ and $B g l \mathrm{II}(0.8 \mathrm{kbp})$ digests of pHG201 and pHG205 (results not shown). One possible explanation of these results is that long TIRs (more than $7 \mathrm{kbp}$ ) resulted in terminal fragments of identical size. However, the macrorestriction maps of pHG201 and pHG205 do not show an extensive symmetry of the termini. In order to discriminate between the two ends, DNA of pHG201 was digested with the rare-cutting enzyme AsnI and hybridized with the $0.6 \mathrm{kbp}$ EcoRI right-end terminal fragment of pHG207 as probe (data not shown). Only the $21 \mathrm{kbp} A s n I$ fragment, representing the right end of pHG201 (Fig. 1; Kalkus et al., 1990), hybridized with the probe. The $190 \mathrm{kbp}$ AsnI fragment, representing the left end of pHG201, did not give any signal.

To investigate an alternative possibility, that short TIRs were not detected by the probe under the conditions used for the previous experiments, SalI and BgllI digests of pHG201 and pHG205 were hybridized to an oligonucleotide probe corresponding to the terminal 17 bases of the $3^{\prime}$ end of pHG207. Even under conditions of low stringency $\left(55^{\circ} \mathrm{C}, 6 \times\right.$ SSC, $1 \%$ SDS $)$ no fragments other than the $2.3 \mathrm{kbp} \mathrm{Sall}$ fragment and the $0.8 \mathrm{kbp}$ BglII fragment could be identified in pHG201 and pHG205 carrying the terminal sequence of pHG207 (data not shown).

\section{Identification of the terminal fragments by gel retardation experiments}

A general feature of the linear replicons of actinomycetes is that TPs are covalently bound to the $5^{\prime}$ end of the DNA. Therefore, gel retardation experiments were done to investigate whether the Rhodococcus linear plasmid end fragments homologous to the terminal sequence of pHG207, identified above, had this feature. Restriction fragments were produced by SalI and BamHI of DNA of pHG204 isolated with and without proteolytical treatment (Fig. 4a). The resulting DNA fragments were analysed by Southern hybridization using the $0.6 \mathrm{kbp}$ EcoRI fragment of pHG207 as a probe. The indicated sizes of the fragments mentioned below were determined from proteolytically treated DNA samples. The mobility of the $3.0 \mathrm{kbp}$ and the $4.0 \mathrm{kbp}$ Sall fragment, and a $0.9 \mathrm{kbp}$ and a $7.6 \mathrm{kbp} \mathrm{BamHI}$ fragment, all of which share homologous sequences with the terminal sequence of pHG207, were retarded by proteins (arrowheads in Fig. 4a). The $1.9 \mathrm{~kb}$ Sall fragment, which gave only a faint signal (position marked with an asterisk in Fig. 4a), was not influenced by treatment with proteinase $\mathrm{K}$ and was therefore identified as an internal fragment of pHG204. No further retarded fragments could be detected.

Results from the Southern hybridization of Sall-digested DNA simultaneously with the $0.6 \mathrm{kbp}$ right-ended 


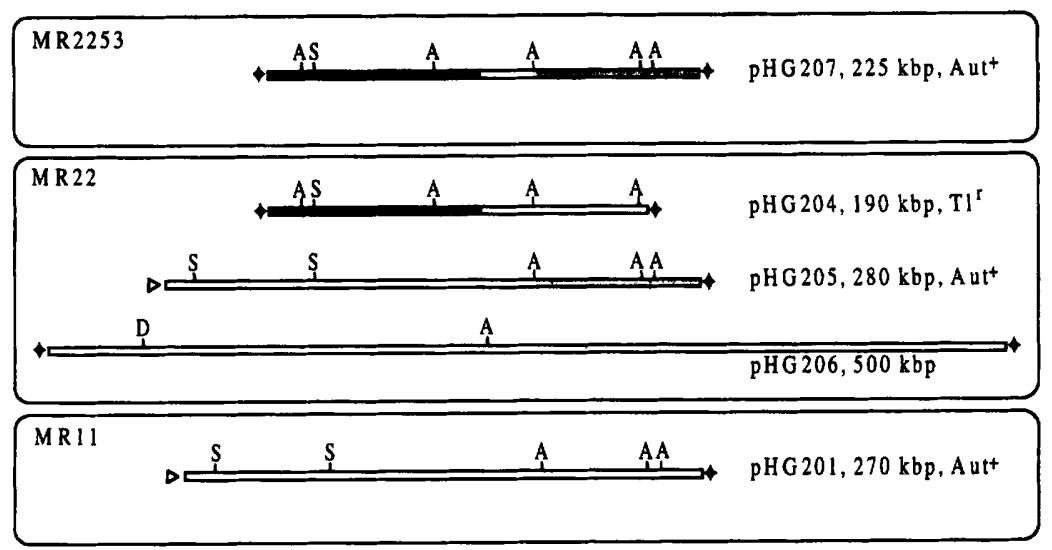

Fig. 1. Macrorestriction maps of linear plasmids of $R$. opacus strains. Simplified restriction maps of the linear plasmids pHG201, pHG204, pHG205, pHG206 and pHG207 are shown. Black diamonds indicate the termini that have homology to the $0.6 \mathrm{kbp}$ EcoRI fragment of pHG207 (right end). White triangles indicate that the left ends of pHG201 and pHG205 are similar by hybridization. Shaded areas indicate the regions of pHG207 which are, with respect to the restriction patterns and hybridizations, homologous to their parental plasmids pHG204 and pHG205 (Kalkus et al., 1993). The non-shaded region of pHG207 has not yet been assigned to pHG204 or pHG205 according to the restriction map. Restriction sites: A, Asnl; S, Spel; D, Dral. Phenotypes: Aut ${ }^{+}$, Aut character; $\mathrm{TI}^{r}$, thallium resistance.

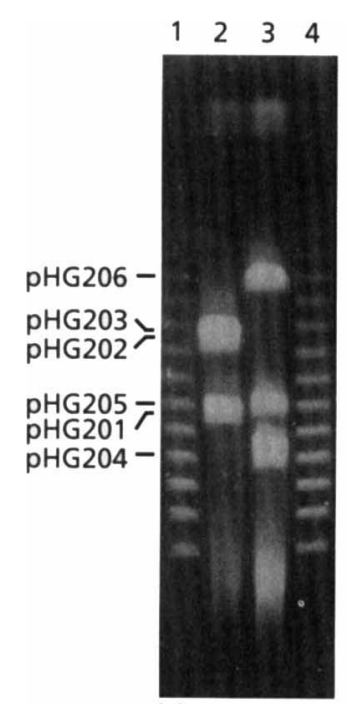

(a)

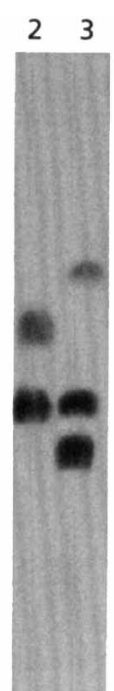

(b)

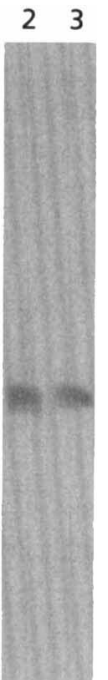

(c)

Fig. 2. Detection of regions homologous with the terminal sequences of pHG207 and pHG201 in other linear plasmids. (a) PFGE separation of total DNA preparation in agarose plugs of strains MR11 and MR22. (b) Southern blot analysis of (a) with the $0.6 \mathrm{kbp}$ EcoRI fragment of pHG207 (right end) as probe. (c) Southern blot analysis of (a) with the $1.15 \mathrm{kbp}$ Sall fragment of pHG201 (left end) as probe. Lanes 1 and 4, $\lambda$ ladder as size standard; lane 2, MR11; lane 3, MR22. PFGE programme: 24 h, pulse time ramp from 20 to $80 \mathrm{~s}$.

terminal EcoRI fragment of pHG207 and a $16 \mathrm{kbp}$ leftend terminal SpeI fragment of pHG201 as probes, is shown in Fig. 4(b) with and without proteinase $\mathrm{K}$ treatment. Only the $2.3 \mathrm{kbp}$ and $1.15 \mathrm{kbp}$ Sall fragments of pHG201 appeared to be affected by the protease treatment, suggesting that they contain the plasmid's termini. In a similar experiment, but with only the $0.6 \mathrm{kbp}$ right end of pHG207 as a probe (Fig. 4c), a $2.3 \mathrm{kbp}$ SalI fragment of pHG205 was identified as containing one of that plasmid's terminal sequences.

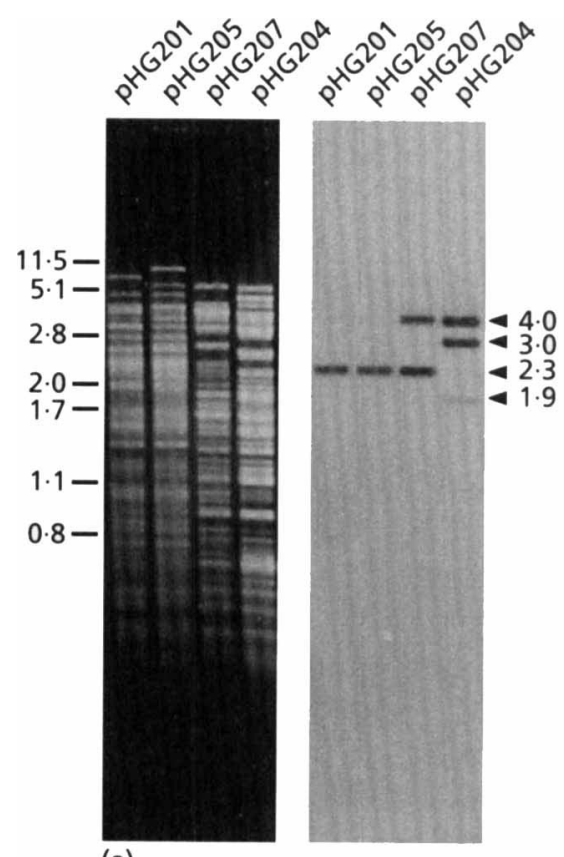

(a)

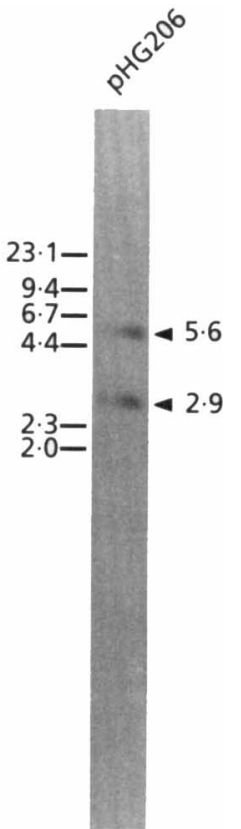

(b)
Fig. 3. Detection of regions homologous with the terminal sequence of pHG207 in restriction patterns of the linear plasmids pHG201, pHG204, pHG205 and pHG206. (a) PFGE separation of Sall-digested isolated plasmid DNA and Southern blot analysis with the $0.6 \mathrm{kbp}$ EcoRI fragment of pHG207 (right end) as probe. (b) Southern blot analysis of Sall-digested pHG206 with the $0.6 \mathrm{kbp} \mathrm{EcoRI} \mathrm{fragment} \mathrm{of} \mathrm{pHG207} \mathrm{(right} \mathrm{end)}$ as probe. To the left, the size (kbp) and location of the fragments of the size standard are indicated. To the right, the size (kbp) of the hybridizing fragments is given. PFGE programme: $30 \mathrm{~min}$ pulse time $0.1 \mathrm{~s}, 30 \mathrm{~min}$ pulse time $1 \mathrm{~s}, 11 \mathrm{~h}$ pulse time ramp from 1 to $10 \mathrm{~s}$.

The other terminus of pHG205 was localized to a $1.15 \mathrm{kbp}$ SalI fragment by hybridization with the $1.15 \mathrm{kbp}$ Sall fragment from pHG201 (cloned and labelled) as probe (Fig. 4 d). 


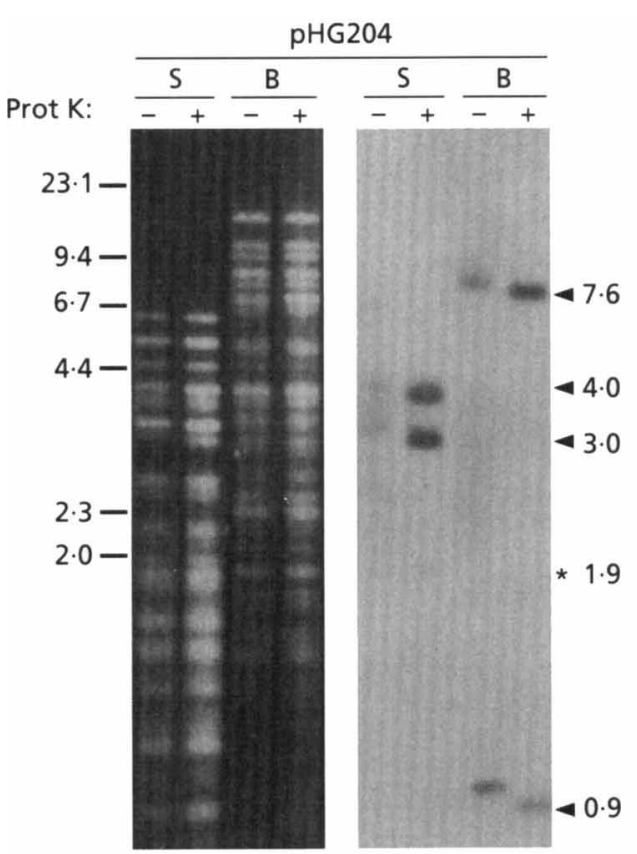

(a)

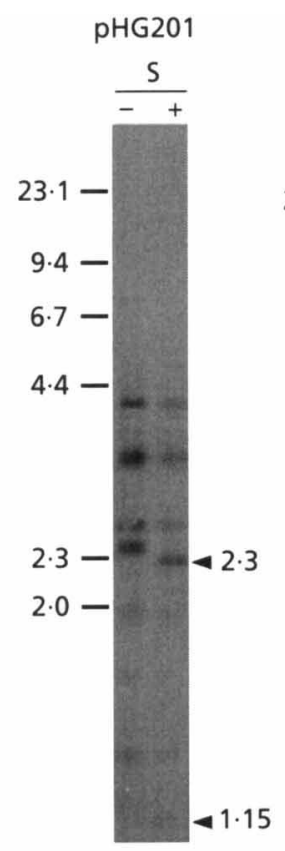

(b)

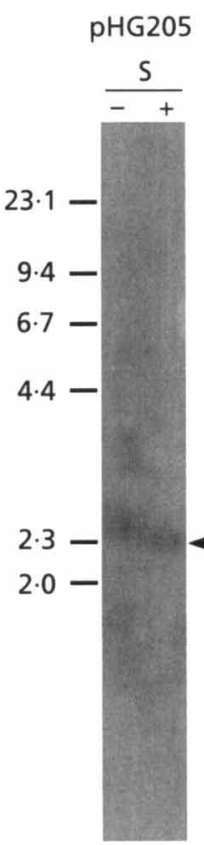

(c)

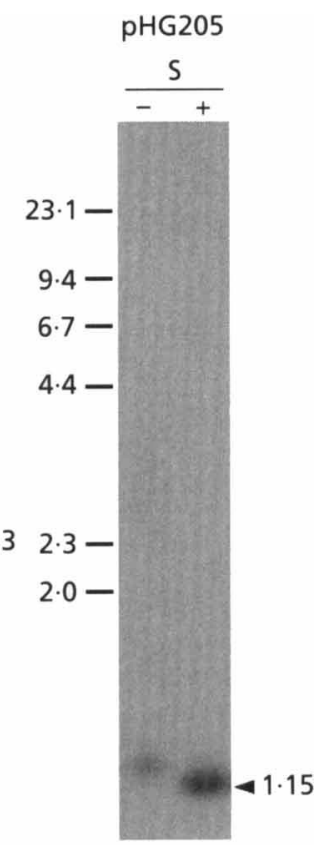

(d)

Fig. 4. Change of the electrophoretic mobility of restriction fragments of pHG204, pHG201 and pHG205 after proteolytic treatment. (a) Restriction pattern of pHG204 produced by Sall (S) and BamHI (B) and Southern blot analysis using the $0.6 \mathrm{kbp}$ EcoRI fragment of pHG207 as a probe. (b-d) Southern blot analysis of: (b) Sall-digested pHG201, using the $0.6 \mathrm{kbp}$ EcoRI fragment of pHG207 (right end) and the $16 \mathrm{kbp}$ Spel fragment of pHG201 (left end) as probes; (c) Sa/l-digested pHG205, using the $0.6 \mathrm{kbp}$ EcoRl fragment of pHG207 (right end) as a probe; (d) Sall-digested pHG205, using the 1.15 kbp Sall fragment of pHG201 (left end) as a probe. Prot K, plasmid DNA isolated without $(-)$ or with $(+)$ proteinase K treatment. To the left, the size $(\mathrm{kbp})$ and location of the fragments of the size standards are indicated. Arrowheads indicate fragments that showed a changed mobility. The size of these fragments is given in kbp. PFGE programme: $30 \mathrm{~min}$ pulse time $0.1 \mathrm{~s}, 30 \mathrm{~min}$ pulse time $1 \mathrm{~s}, 11 \mathrm{~h}$ pulse time ramp from 1 to $10 \mathrm{~s}$.

\section{Validation of the cloning strategy for linear plasmid termini}

After restriction digestion the two resulting end fragments of a linear plasmid should have unequal ends one end produced by the restriction endonuclease used and one end of the linear plasmid. The ends of pSLA2 were shown to be blunt-ended by direct chemical sequencing (Hirochika et al., 1984). However, the $5^{\prime}$ ends of pSLA2 and pHG207 were blocked even after proteolytic treatment, probably by remaining amino acid residues (Hirochika \& Sakaguchi, 1982; Kalkus et al., 1993). The termini of pHG207 were ligated without a special treatment to the blunt end side of a vector (Kalkus et al., 1993). Because it was crucial to show that the very ends of a linear plasmid can be cloned by this method, direct sequencing was applied to pHG207. A primer was chosen whose sequence represented bases

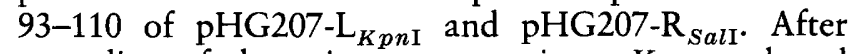
annealing of the primer to proteinase $\mathrm{K}$-treated and alkali-denatured pHG207 DNA the sequencing reactions were carried out. The hybrid plasmids pHG207$\mathrm{L}_{K p n I}$ and $\mathrm{pHG} 207-\mathrm{R}_{\text {SalI }}$ were sequenced with the same primer. The sequencing reactions were analysed in parallel (Fig. 5).

Strong bands in all four lanes $(\mathrm{A}, \mathrm{C}, \mathrm{G}, \mathrm{T})$ indicate the abortion of the polymerase reaction at the native linear plasmid end. The lower bands in these lanes occur at exactly the same position as the last nucleotide of the cloned termini in pHG207- $\mathrm{L}_{K p n \mathrm{I}}$ and pHG207- $\mathrm{R}_{\text {SalI }}$. The four bands at one position higher might indicate a variable end of pHG207 differing by one nucleotide. Court \& Bertrand (1991) reported that T7 DNA polymerase was able to elongate the newly synthesized DNA strand by one nucleotide beyond the end of the template strand. The polymerase used in our experiments is a modified T7 DNA polymerase (Tabor \& Richardson, 1989). Therefore, we assume that the upper bands observed in our experiments result from such an additional template-independent elongation.

These experiments indicated that direct ligation of the plasmid ends is a suitable method to clone the very end of a linear plasmid.

\section{Cloning and sequence analysis of terminal fragments of pHG201 and pHG204}

For further analysis of the termini of wild-type linear plasmids from strains MR11 and MR22, the $1.15 \mathrm{kbp}$ and the $2.3 \mathrm{kbp}$ SalI fragment of pHG201, and the $3.0 \mathrm{kbp}$ Sall fragment of pHG204, were isolated and cloned. The left end of pHG204 is assumed to be the same as the left end of pHG207, which has already been sequenced (Kalkus et al., 1993). 


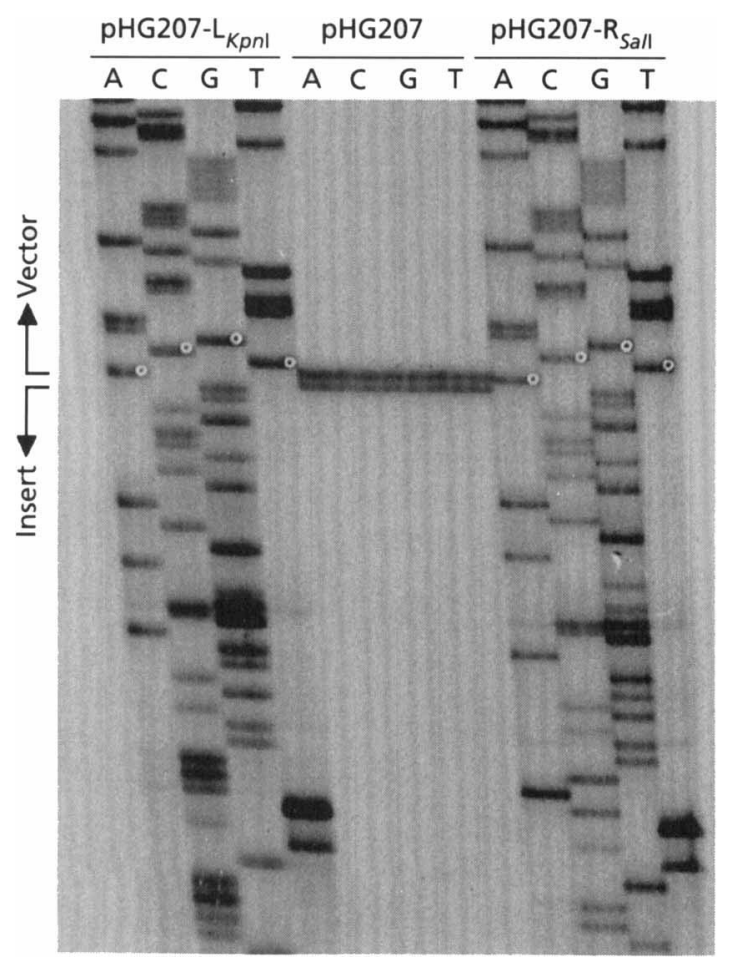

Fig. 5. Direct sequencing of pHG207. An autoradiogram of the sequencing ladder of pHG207- $L_{K p n l}$, pHG207 and pHG207- $R_{\text {Sall }}$ is shown. In the lanes of pHG207 only the two bands resulting from termination of the polymerase reaction at the very ends of pHG207 (see text) are visible. Dots mark the first nucleotides belonging to the vector DNA.

The purified fragments were inserted in a Sall/EcoRVcut vector (pBluescript SKM13+) and transferred via electroporation into $E$. coli XL1 Blue. Among the few transformants obtained, two positive clones were identified carrying hybrid plasmids containing the $3.0 \mathrm{kbp}$ Sall fragment of pHG204, and four and two clones containing the $1.15 \mathrm{kbp}$ and the $2.3 \mathrm{kbp}$ Sall fragment of pHG201, respectively. The resulting plasmids are re-

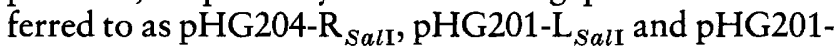
$\mathrm{R}_{\text {SalI }}$ (Table 2). To ensure the uniformity of the clones obtained, the hybrid plasmids were examined by a detailed restriction analysis and by sequencing of the blunt-end junctions between vector and insert DNA. All clones gave identical results.

A $1116 \mathrm{bp}$ length of pHG204- $\mathrm{R}_{\text {SalI }}$ was sequenced starting at the blunt-end ligation site (data not shown; GenBank/EMBL AF001834). Alignment with the nucleotide sequence of $\mathrm{pHG} 207-\mathrm{L}_{K p n \mathrm{I}}$, which is believed to originate from the left terminal part of pHG204 (Kalkus et al., 1993), revealed a homology of more than $99 \%$ within the terminal $1016 \mathrm{bp}$. The TIR (1016 bp) was clearly separated from the adjoining sequences which do not share significant homology. The only differences within the 'right' and 'left' TIRs of pHG204 were at positions 894 ( $G$ in $p H G 204-R_{\text {Sall }}$; $C$ in

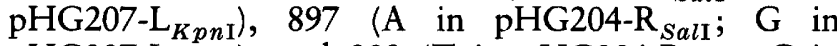
pHG207- $\mathrm{L}_{K p n \mathrm{I}}$ ), and 902 ( $\mathrm{T}$ in $\mathrm{pHG} 204-\mathrm{R}_{\text {SalI }}$; $\mathrm{C}$ in

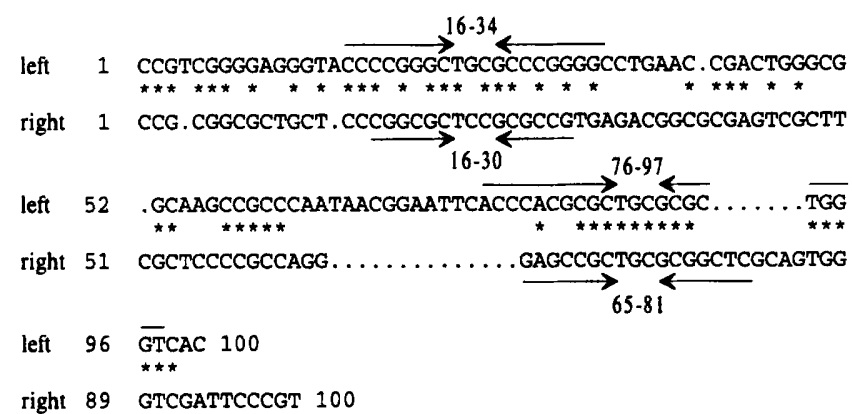

Fig. 6. Alignment of the terminal 100 bases of pHG201. Dots indicate introduced gaps; asterisks mark homologies of the left with the right end. Inverted repeats are marked with converging arrows.

pHG207- $\mathrm{L}_{K p n \mathrm{I}}$ ). The difference at position 894 affected a BamHI site, which is therefore missing in the right terminus of pHG204. This was confirmed by the results obtained in the gel retardation experiment (Fig. 4a): instead of two identical fragments of $0.9 \mathrm{kbp}$, two differently sized BamHI fragments $(0.9 \mathrm{kbp}$ and $7.6 \mathrm{kbp})$ contained the two termini.

The insert of the hybrid plasmid pHG201-R Sal $_{\text {, }}$, carrying the $2.3 \mathrm{kbp}$ SalI fragment of pHG201, was partially sequenced starting at the blunt-end ligation site (data not shown; GenBank/EMBL AF007825). Alignment of the nucleotide sequence obtained (1200 bp) with the sequence of $\mathrm{pHG} 207-\mathrm{R}_{\text {SalI }}$ revealed $100 \%$ homology of the analysed region. Hybridization of the wildtype linear plasmids with pHG201- $\mathrm{L}_{\text {SalI }}$ as probe revealed the occurrence of the left terminal sequence of pHG201 in pHG201 and pHG205 (Fig. 2c). No other linear plasmid gave a signal. The sequence of the $1.15 \mathrm{kbp}$ insert of pHG201- $\mathrm{L}_{S a l \mathbf{I}}$ was fully determined (not shown; GenBank/EMBL AF001835). Two potential open reading frames (ORF 201L1 [1152-235 (stop)] and 201L2 [247(start)-1152]) were detected. Both have a high probability of coding when checked for codon usage and GC bias of the third position of the triplets by the program CODONPREFERENCE (Devereux $e t$ al., 1984). Search in databases (EMBL release 49.0; SWISS-PROT release 34.0) using the search facilities MPsrch (University of Edinburgh) and BLAST (Altschul et al., 1990) did not reveal any significant homology.

Alignment of the right and left terminal sequences of pHG201 revealed a similarity of only $65 \%$ for the 34 terminal bases of the left end with the 32 terminal bases of the right end, and a perfect TIR of only 3 bp (Fig. 6).

\section{DISCUSSION}

Most of the linear plasmids so far described in bacteria have been found among actinomycetes, especially within the genera Streptomyces and Rhodococcus. Recently, linear plasmids were also found in the genus Mycobacterium (Picardeau \& Vincent, 1997). The chromosomes of several Streptomyces species have been shown 
to be linear as well (Lin et al., 1993; Gravius et al., 1994; Lezhava et al., 1995; Leblond et al., 1996). The common features of the linear replicons in Streptomyces are perfect or imperfect TIRs, with proteins bound to their ends. The lengths of TIRs are not uniform: the large linear plasmids SCP1 (350 kbp) and pPZG101 (387 kbp) have very long TIRs of more than $80 \mathrm{kbp}$ (Kinashi et al., 1991; Gravius et al., 1994), and also the linear chromosomes (about $8 \mathrm{Mb}$ ) possess TIRs of about $25 \mathrm{kbp}(S$. lividans, S. griseus) or even $210 \mathrm{kbp}$ (S. ambofaciens) (Lin et al., 1993; Lezhava et al., 1995; Leblond et al., 1996). Smaller linear plasmids like pSCL1 (11.7 kbp) and pSLA2 (17 kbp) have TIRs of less than $1 \mathrm{kbp}$ (Wu $\&$ Roy, 1993; Hirochika et al., 1984). The linear plasmid SLP2 $(50 \mathrm{kbp}$ ) carries a TIR of only $44 \mathrm{bp}$ (Chen et al., 1993). Thus there is not a fixed correlation between the size of the replicon and the length of the TIR, but it could be generalized that large linear replicons carry long TIRs. The chromosome of $S$. lividans and the plasmid pSLA2 were shown to carry a centrally located functional origin of replication, and for some of the linear replicons a conversion into a circular form was reported (Zakrzewska-Czerwinska \& Schrempf, 1992; Chang \& Cohen, 1994; Shiffman \& Cohen, 1992; Lin et al., 1993; Volff et al., 1997). The ends are not necessarily the origin of replication of the linear replicons (Chang \& Cohen, 1994). However, in case of the S. lividans chromosome, the circularization is accompanied by genetic instability and genomic rearrangements (Volff $e t$ al., 1997). The function and essential features of the telomeric region remains unclear.

The aim of this study was to analyse the termini of the linear plasmids in the genus Rhodococcus, in order to obtain more information on the general telomeric structure. The first detailed study on a linear plasmid of $R$. opacus was performed using pHG207 $(225 \mathrm{~kb})$. With its TIR of $583 / 560 \mathrm{bp}$ and proteins covalently bound to the $5^{\prime}$ ends of the plasmid it possesses all features described for the linear plasmids in Streptomyces. However, in comparison to the large linear plasmids SCP1 and pPZG101, the TIR detected is relatively short. Because pHG207 was shown to be the product of a recombination between the wild-type linear plasmids pHG204 and pHG205, it seemed reasonable to suggest that TIRs are a general feature of the linear plasmids of $R$. opacus. Indeed, we could show that all linear plasmids of the wild-type strains MR22 and MR11 carry sequences homologous to the terminal sequence of pHG207. Homologous sequences, detectable by hybridization between different linear replicons, were also reported for S. lividans : about $16 \mathrm{kbp}$ of the right end of the linear plasmid SLP2 was identical to the terminal sequences of the chromosome (Chen et al., 1993; Lin et al., 1993). Plasmid SLP2 shares homologous sequences with the linear plasmid pSPA1 from $S$. parvulus as well (Chen et al., 1993).

The sequence analysis of the terminal part of pHG204 reported in this paper revealed a nearly perfect TIR of $1016 \mathrm{bp}$, with only three mismatches between the right and left ends. Because the alignment was done using the right end of pHG207 and the left end of pHG204, the differences could have been due to the different sources of the sequences. However, because one of these differences concerned a Bam $\mathrm{HI}$ restriction site in pHG204 the differences could be verified via different restriction patterns in the TIR of pHG204. A similar feature was described for PSCL1, where the perfect TIR, which is $894 \mathrm{bp}$ in size, is interrupted by a 3 base mismatch after $690 \mathrm{bp}$. In contrast to the sharp boundaries of the TIRs found in pHG207 and pHG204, the TIRs of pSCL1 and pSLA2 are followed by a less homologous zone of about $25 \mathrm{bp}$ and $180 \mathrm{bp}$, respectively, with a 'patched' homology (Wu \& Roy, 1993; Hirochika et al., 1984). A TIR can also be assumed to be present in pHG206, because the regions which show homology with the terminal sequence of pHG207 are located at the two ends of pHG206 (Fig. 1 and unpublished results).

None of the linear plasmids examined in this study carries TIRs comparable in length to those found in the large linear replicons of Streptomyces. Furthermore, the linear plasmid pHG201 was shown to have no real TIR. The first mismatch between the left and the right end appears after the third nucleotide. The homology of the terminal $34 / 32$ bases is only $65 \%$, which is even less than the homology with telomeric sequences of other linear plasmids (e.g. $73 \%$ for the left end of pHG201 versus the ends of SLP2 or $\mathrm{pSCL}$ ). We assume the same is true for the Aut element pHG205, because the terminal fragments of pHG201 and pHG205 are homologous and identical in size. These results and the similar restriction patterns of both plasmids (Fig. 3) provoke the assumption of a common ancestor. However, the macrorestriction maps of the two plasmids are different. The finding of a transposable element in MR11 by Grzeszik et al. (1997a) offers a reasonable explanation, insofar as transposition events may have caused rearrangements and deletions in the plasmid.

To our knowledge, pHG201 and pHG205 are the only reported examples of actinomycete linear plasmids that do not show a striking homology between their 'right' and 'left' ends. However, the well-studied phage $\phi 29$, which serves as a model for TP-primed replication, also carries very short TIR (6 bp) (Yoshikawa et al., 1981; Escarmis \& Salas, 1981; Salas et al., 1995). The replication of the genome of $\phi 29$ starts with a slidingback mechanism: the TP-dependent DNA polymerase binds to the single-stranded $3^{\prime}$ region of $\phi 29$ and catalyses the linkage of the TP and a nucleotide using the second nucleotide of the $3^{\prime}$ strand as template (Mendez et al., 1992). After the linkage is established, the TP nucleotide complex slides back to the last nucleotide. Therefore, for a successful replication a repetition of the terminal nucleotide is essential (Mendez et al., 1992). Such a sliding-back mechanism was also reported for the replication of adenoviral DNA and was suggested as a general mechanism for TP-dependent replications. (Graham et al., 1989; Mendez et al., 1992). Looking for a possible template nucleotide within the terminal 10 bases of pHG201 only the G at the second position could 
fulfil the function insofar as it is a repetition of the terminal $\mathrm{G}$ and it is in the same distance towards the end at both sides.

Our results suggest that it is not the TIRs themselves, but certain structures like inverted or direct repeats at the ends, that are necessary for the complete replication and/or stability of a linear plasmid. TIRs are more likely to be the result of recombination, for example to rescue a linear plasmid after the loss of one telomer. Comparison and alignment of the terminal sequences of pHG201 showed two inverted repeats which have the same central motif (GCTXCGC) and a high GC-content (Fig. 6, positions 16-34, 76-97 in pHG201- $\mathrm{L}_{S a l \mathrm{I}}$ and 16-30, 65-81 in pHG201- $\left.\mathrm{R}_{\text {salI }}\right)$. Analogous inverted repeats were also found in pSCL, pSLA2 and SLP2 (Wu \& Roy, 1993; Hirochika et al., 1984; Chen et al., 1993). Chen (1996) described a model, suggested by S. N. Cohen, where the telomers, which are left as a singlestranded 3' overhang after replication of the main part of the plasmid from a central located origin, are folded at inverted repeats to form specific secondary structures. This structure might be the signal for the TP-dependent DNA polymerase to complete the $5^{\prime}$ strand. The inverted repeats mentioned above could produce such hairpin structures, which may also function during replication as a termination signal or hindrance for DNA polymerase. A termination of the polymerization hypothetically starting from the TP would restrict the action of the postulated specific TP-dependent DNA polymerase to the telomers. A termination signal for the DNA polymerase which starts from an internal origin would leave a defined 3 ' overhang. Indeed, Chang \& Cohen (1994) detected molecules of pSLA2 with singlestranded parts of around $280 \mathrm{bp}$ at their ends which might be an intermediate form of replication. Another possible role of the conserved inverted repeats is the function as binding sites for proteins which might be essential for the maintenance or replication of the linear plasmid.

Analyses of linear plasmids of other species of Rhodococcus are under way. The information gained will contribute to the elucidation of the general telomeric structure of linear wild-type plasmids.

\section{ACKNOWLEDGEMENTS}

This work was supported by a grant from the Deutsche Forschungsgemeinschaft ( $\operatorname{Re} 842 / 1-2)$. We thank $\operatorname{Dr} M$. Keßeler for critical reading of the manuscript.

\section{REFERENCES}

Aggag, M. \& Schlegel, H. G. (1973). Studies on a Gram-positive hydrogen bacterium, Nocardia opaca 1b. I. Description and physiological characterization. Arch Microbiol 88, 299-318.

Altschul, S. F., Gish, W., Miller, W., Myers, E. W. \& Lipman, D. J. (1990). Basic local alignment search tool. J Mol Biol 215, 403-410.

Ausubel, F. M., Brent, R., Kingston, R. E., More, D. D., Seidman, J. G., Smith, J. A. \& Struhl, K. (1987). Current Protocols in Molecular Biology. New York: Wiley.
Chang, P.-C. \& Cohen, S. N. (1994). Bidirectional replication from an internal origin in a linear Streptomyces plasmid. Science 265, 952-954.

Chen, C. W. (1996). Complications and implications of linear bacterial chromosomes. Trends Genet 12, 192-196.

Chen, C. W., Yu, T.-W., Lin, Y.-S., Kieser, H. M. \& Hopwood, D. A. (1993). The conjugative plasmid SLP2 of Streptomyces lividans is a $50 \mathrm{kbp}$ linear molecule. Mol Microbiol 7, 925-932.

Court, D. A. \& Bertrand, H. (1991). A method for sequencing uncloned termini of linear plasmids. Nucleic Acids Res 19, 1714.

Crespi, M., Messens, E., Caplan, A. B., Van Montagu, M. \& Desomer, J. (1992). Fasciation induction by the phytopathogen Rhodococcus fascians depends upon a linear plasmid encoding a cytokinin synthase gene. EMBO J 11, 795-804.

Dabrock, B., Riedel, J., Bertram, J. \& Gottschalk, G. (1992). Isopropylbenzene (cumene) - a new inducer substrate for the isolation of trichloroethene-degrading bacteria. Arch Microbiol 158, 9-13.

Dabrock, B., Keßeler, M., Averhoff, B. \& Gottschalk, G. (1994). Identification and characterization of a transmissible linear plasmid from Rbodococcus erythropolis BD2 specifying isopropylbenzene and trichloroethene (TCE) catabolism. Appl Environ Microbiol 60, 853-860.

Devereux, J., Haeberli, P. \& Smithies, O. (1984). A comprehensive set of sequence analysis programs for the VAX. Nucleic Acids Res $12,387-395$.

Escarmis, C. \& Salas, M. (1981). Nucleotide sequence at the termini of the DNA of Bacillus subtilis phage $\phi 29$. Proc Natl Acad Sci USA 78, 1446-1450.

Graham, F. L., Rudy, J. \& Brinkley, P. (1989). Infectious circular DNA of human adenovirus type 5: regeneration of viral DNA termini from molecules lacking terminal sequences. $E M B O J \mathbf{8}$, 2077-2085.

Gravius, B., Glocker, D., Pigac, J., Pandza, K., Hranueli, D. \& Cullum, J. (1994). The $387 \mathrm{kbp}$ linear plasmid pPZG101 of Streptomyces rimosus and its interactions with the chromosome. Microbiology 140, 2271-2277.

Grzeszik, C., Lübbers, M., Reh, M. \& Schlegel, H. G. (1997a). Genes encoding the NAD-reducing hydrogenase of Rbodococcus opacus MR11. Microbiology 143, 1271-1286.

Grzeszik, C., Roß, K., Schneider, K., Reh, M. \& Schlegel, H. G. (1997b). Location, catalytic activity, and subunit composition of NAD-reducing hydrogenases of some Alcaligenes strains and Rhodococcus opacus MR22. Arch Microbiol 167, 172-176.

Hirochika, H. \& Sakaguchi, K (1982). Analysis of linear plasmids isolated from Streptomyces: association of protein with the ends of the plasmid DNA. Plasmid 7, 59-65.

Hirochika, H., Nakamura, K. \& Sakaguchi, K. (1984). A linear DNA plasmid from Streptomyces rochei with terminal repetition of 614 base pairs. EMBO J 3, 761-766.

Kalkus, J., Reh, M. \& Schlegel, H. G. (1990). Hydrogen autotrophy of Nocardia opaca strains is encoded by linear megaplasmids. $J$ Gen Microbiol 136, 1145-1151.

Kalkus, J., Dörrie, C., Fischer, D., Reh, M. \& Schlegel, H. G. (1993). The giant linear plasmid pHG207 from Rhodococcus sp. encoding hydrogen autotrophy: characterization of the plasmid and its termini. J Gen Microbiol 139, 2055-2065.

Khandjian, E. W. (1987). Optimized hybridization of DNA blotted and fixed to nitrocellulose and nylon membranes. Bio/ Technology 5, 165-167.

Kinashi, H., Shimaji-Murayama, M. \& Hanafusa, T. (1991). 
Nucleotide sequence analysis of the unusually long terminal inverted repeats of a giant linear plasmid, SCP1. Plasmid 26, 123-130.

Klatte, S., Kroppenstedt, R. M. \& Rainey, F. A. (1994). Rhodococcus opacus sp. nov., an unusual nutritionally versatile Rhodococcus species. Syst Appl Microbiol 17, 355-360.

Leblond, P., Fischer, G., Francou, F.-X., Berger, F., Guerineau, M. \& Decaris, B. (1996). The unstable region of Streptomyces ambofaciens includes $210 \mathrm{kbp}$ terminal inverted repeats flanking the extremities of the linear chromosomal DNA. Mol Microbiol 19, 261-271.

Lezhava, A., Mizukami, T., Kajitano, T., Kameoka, D., Redenbbach, M., Shinkawa, H., Nimi, O. \& Kinashi, H. (1995). Physical map of the linear chromosome of Streptomyces griseus. J Bacteriol 177, 6492-6498.

Lin, Y.-S., Kieser, H. M., Hopwood, D. A. \& Chen, C. W. (1993). The chromosomal DNA of Streptomyces lividans 66 is linear. Mol Microbiol 10, 923-933.

McClelland, M., Jones, R., Patel, Y. \& Nelson, M. (1987). Restriction endonucleases for pulsed field mapping of bacterial genomes. Nucleic Acids Res 15, 5985-6005.

Mendez, J., Blanco, L., Esteban, J. A., Bernad, A. \& Salas, M. (1992). Initiation of $\phi 29$ DNA replication occurs at the second $3^{\prime}$ nucleotide of the linear template: a sliding-back mechanism for protein-primed DNA replication. Proc Natl Acad Sci USA 89, 9579-9583.

Oelmuller, U., Krüger, N., Steinbuchel, A. \& Friedrich, C. G. (1990). Isolation of prokaryotic RNA and detection of specific messengerRNA with biotinylated probes. J Microbiol Methods 11, 72-81.

Picardeau, M. \& Vincent, V. (1997). Characterization of large linear plasmids in mycobacteria. J Bacteriol 179, 2753-2756.

Rainey, F. A., Burghardt, J., Kroppenstedt, R. M., Klatte, S. \& Stackebrandt, E. (1995). Phylogenetic analysis of the genera Rhodococcus and Nocardia and evidence for the evolutionary origin of the genus Nocardia from within the radiation of Rhodococcus species. Microbiology 141, 523-528.

Sakaguchi, K. (1990). Invertrons, a class of structurally and functionally related genetic elements that includes linear DNA plasmids, transposable elements, and genomes of Adeno-type viruses. Microbiol Rev 54, 66-74.

Salas, M., Freire, R., Soengas, M. S., Esteban, J. A., Mendez, J., Bravo, A., Serrano, M., Blasco, M. A., Lazaro, J. M., Blanco, L., Gutierrez, C. \& Hermoso, J. M. (1995). Protein-nucleic acid interactions in bacteriophage $\phi 29$ DNA replication. FEMS Microbiol Rev 17, 73-82.

Sanger, F., Nicklen, H. \& Coulson, A. R. (1977). DNA sequencing with chain-terminating inhibitors. Proc Natl Acad Sci USA 77, 2611-2615.

Schneider, K., Cammack, R. \& Schlegel, H. G. (1984). Content and localization of FMN, Fe-S clusters and nickel in the NAD-linked hydrogenase of Nocardia opaca 1b. Eur J Biochem 142, 75-84.

Sensfuss, C., Reh, M. \& Schlegel, H. G. (1986). No correlation exists between the conjugative transfer of the autotrophic character and that of plasmids in Nocardia opaca strains. J Gen Microbiol 132, 997-1007.

Shiffman, D. \& Cohen, S. N. (1992). Reconstruction of a Streptomyces linear replicon from separately cloned fragments: existence of a cryptic origin of circular replication within the linear plasmid. Proc Natl Acad Sci USA 89, 6129-6133.

Tabor, S. \& Richardson, C. C. (1989). Selective inactivation of the exonuclease activity of bacteriophage T7 DNA polymerase by in vitro mutagenesis. J Biol Chem 264, 6447-6458.

Vantomme, R., Elia, S., Swings, J. \& De Ley, J. (1982). Corynebacterium fascians (Tilford 1936) Dowson 1942, the causal agent of leafy gall on lily crops in Belgium. Parasitica 38, 183-192.

Vieira, J. \& Messing, J. (1987). Production of single-stranded plasmid DNA. Methods Enzymol 153, 3-11.

Volff, J.-N., Viell, P. \& Altenbuchner, J. (1997). Artificial circularization of the chromosome with concomitant deletion of its terminal inverted repeats enhances genetic instability and genome rearrangement in Streptomyces lividans. Mol Gen Genet 253, 753-760.

Waterbury, P. G. \& Lane, M. J. (1987). Generation of lambda phage concatemers for use as pulsed field electrophoresis size markers. Nucleic Acids Res 15, 3930.

Wu, X. \& Roy, K. L. (1993). Complete nucleotide sequence of a linear plasmid from Streptomyces clavuligerus and characterization of its RNA transcript. J Bacteriol 175, 37-52.

Yoshikawa, H., Friedmann, T. \& Ito, J. (1981). Nucleotide sequences at the termini of $\phi 29$ DNA. Proc Natl Acad Sci USA 78, 1336-1340.

Zaborosch, C., Schneider, K., Schlegel, H. G. \& Kratzin, H. (1989). Comparison of the $\mathrm{NH}_{2}$-terminal amino acid sequences of the four non-identical subunits of the NAD-linked hydrogenases from Nocardia opaca 1b and Alcaligenes eutrophus H16. Eur J Biochem 181, 175-180.

Zakrzewska-Czerwinska, J. \& Schrempf, H. (1992). Characterization of an autonomously replicating region from the Streptomyces lividans chromosome. J Bacteriol 174, 2688-2693.

Received 3 July 1997; revised 11 November 1997; accepted 28 January 1998. 